\title{
May I have this dance? Dance participation and attendance in Denmark
}

Karol Jan Borowiecki \& Catarina Marvão

TEP Working Paper No. 1816

November 2016

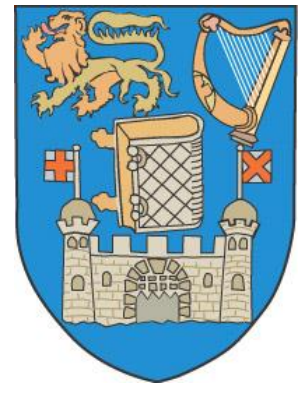

Trinity Economics Papers

Department of Economics

Trinity College Dublin 


\title{
May I have this dance? Dance participation and attendance in Denmark
}

\author{
Karol Jan Borowiecki \\ Department of Business and Economics \\ University of Southern Denmark \\ email: kjb@sam.sdu.dk \\ Catarina Marvão \\ SITE-Stockholm School of Economics \\ email: marvaoc@tcd.ie
}

\begin{abstract}
:
Dancing may be one of the most competitive professions available career-wise, but it is also associated with various positive externalities. Despite the importance of dancing, there is only limited understanding of the profiles of dancers and dance audiences. We fill the gap in the literature by exploiting survey data on cultural preferences and habits in Denmark for 2004. Our approach allows us to identify the socio-economic background of dancers as well as their involvement in other cultural activities. Among other factors, we note that dancers are more frequent attendees at dance performances, have typically lower income and tend to read more, play more video games and visit art exhibits more often. We are further able to disentangle the sample of dancers into various types of dances, allowing so interesting insights on the differences across dancers.
\end{abstract}

Keywords: Dance; cultural preferences; welfare; competitiveness

JEL codes : Z11; Z20; A12; I31 
"Let us read, and let us dance; these two amusements will never do any harm to the world." - Voltaire

\section{Introduction}

Dancing may be one of the most competitive professions available career-wise. The lack of job opportunities and the competitiveness, the inherent expense in costumes and training and the high risk of injuries mean that only few dancers are able to make it their profession. ${ }^{1}$ However, dancing is an activity that comes with positive externalities, as various socioeconomic benefits are experienced by those who practice dance nonprofessionally. Amateur dancing contributes to lowering stress and tension levels by providing a platform for a person to express herself in a completely different way. Dancing contributes to higher levels of happiness, social inclusion and better aging (Skinner, 2013). Dance education has a positive effect on fitness and gross motor development (Ross and Butterfield, 1989), while cultural events (Nicolau, 2010) and, in particular, traditional dances such as flamenco (Aoyama, 2009) and Tanzania traditional dance (Bagashi and Michapondwa, 2009; Răvarand Mahika, 2013) are used in order to boost tourism and so benefit society.

Despite the importance of dancing, very little is known with respect to the profiles of dancers. In this study we use data from a survey on cultural preferences and habits, conducted in Denmark during 2004, in order to reveal information relating to the background of dancers and dance audiences. Denmark is a particularly good candidate for research purposes not only due to the good data availability, but also because it is a surprisingly interesting country as regards to the cultural involvement of its population. According to Eurostat (2011), in 2006, Denmark, as well as the other Nordic countries, presented the highest rates for attendance to performing arts and visits to cultural sites, as well as figuring amongst the top cinema attendees. Perhaps not surprisingly, Nordic countries repeatedly rank as some of the happiest countries in the world. Whilst we do not claim the existence of any causal relationships, there certainly exists a very strong positive correlation between cultural participation and the well-being of a society.

Figure 1 shows an illustrative association between the percentage of persons who have attended a live performance at least once in the last 12 months (Eurostat, 2011) and the HPI well-being index (the Happy Planet Index as in Abdallah et al., 2012). The emerging correlation is equal to 0.64 and statistically significant. At the top of the distribution are the five Nordic countries, with Denmark having obtained the highest wellbeing index. A very similar picture can be obtained using other measures. ${ }^{2}$ For example, a significant and positive correlation of 0.36 exists also between performing arts attendance and life expectancy.

\footnotetext{
${ }^{1}$ See Montgomery and Robinson (2003) for an analysis of earnings and work conditions of dancers, where it is shown that the returns to dance are small and that many dancers have a second job to increase their incomes. The shortage of jobs and low incomes of dancers and the lack of funding available to dance companies, as well as their dependence on the state of the economy have been also discussed by Janaki (2012), Hagoort (2003) and Tobias (2004).

${ }^{2}$ According to the World Happiness Report (2013) Denmark is ranked first in terms of overall well-being. The Legatum Prosperity Index ranked Denmark second in 2013 in prosperity and this for the fourth consecutive year (Forbes, 2013).
} 


\section{[Figure 1 here]}

The economic literature on dance is rather limited. ${ }^{3}$ The attendance at dance events is examined by Schimmelpfennig (1997) who uses data on 16 performances by the UK Royal Ballet and finds that ballet demand is significantly downward-sloping. Seaman (2003) provides a more general debate on cultural versus sports economics and elaborates on the links between these two. A more developed research strand exists in relation to cultural attendance in general. Borgonovi (2004) makes use of US survey data and finds, among others, that art participation is highly correlated with art education but not with prices or geographical concentration.

The market segments for theatre demand are studied by Ateca-Amestoy (2008), who exploit a large survey on US theatres, whilst another study by Grisolia and Willis (2012) uses data from a survey implemented in a regional theatre in the UK. Palma et al. (2013) examine attendance at the spring "fiestas" in Seville, which is shown to be correlated with knowledge, institutional links, past experience and the perceived benefits of these events. Montgomery and Robinson (2003) and Tobias (2004) avail of survey data for the USA and Germany, respectively, to show that there are very low returns to dance, in particular low employment perspectives.

Finally, Cheng and Wen $(2011,2013)$ examine the performing arts in Taiwan, through survey data. The authors find that the audiences of traditional theatre are different from those of other performing arts and that there exists a strong correlation between dance and music.

In this article, we are able to shed light on the socio-economic background of dancers in Denmark in 2004, as well as provide unique insights on their involvement in other cultural activities. Further, we are able to disentangle the sample of dancers into various types of dances, allowing so novel insights on the differences across dancers.

In the next section, the dataset is described. In section 2 we present and discuss various patterns related to the profile of dancers and dance audiences. Section 3 offers some concluding remarks.

\section{Data}

The dataset used in this analysis is part of the survey on the cultural preferences and habits of adults in Denmark (Kulturvaneundersøgelsen, 2004), which was conducted in the period of May to August 2004, via a combination of postal, phone and web-based surveys. Whilst the survey was sent to a random sample of 2888 adults (ages 16-91) registered in the Danish Central Person Register (CPR), only 1830 individuals returned their answers. Although the overall sample size is large, a sample selection bias may exist in the sense that the sample may not accurately represent the population of adults in Denmark: those who chose to answer the survey may be, for example, particularly interested in cultural activities or have more free time than the average Dane. This possible bias is typical for any

\footnotetext{
${ }^{3}$ There exist an interdisciplinary range of studies focusing on the presentation of descriptive studies dedicated to a specific type of dance or a specific topic related to dance. Villella (1994) describes the evolution of classical and folk dance. The modernity of choreographies in East Asia is described by Colome (2005), Swartz (2007) looks at championships in highland dance and Pilcher (2012) describes the issues related to erotic dance.
} 
quantitative research using survey data and has to be taken into consideration when interpreting the results.

The survey includes several questions regarding dance activities as well as a wide range of background controls, such as age, income and occupation. The variety of socioeconomic indicators has unfortunately not been repeated in the later survey of 2012 and, consequently, here we construct our data using the 2004 questionnaire. The sample is slightly skewed towards female respondents (60\% of the sample) and the average age of the respondent is 45 years.

We identify a dancer as someone who answered yes to the question "Do you go dancing/do you dance?" which corresponds to $8.1 \%$ of the individuals who responded to this question (132 out of 1756 respondents). The respondents were also asked to provide further information on the type of dance they practice or about the nature of their dance activities: 20 individuals reported their participation in dance shows or performances, 27 formed part of a dance group and 49 participated in dance training.

\section{Data analysis}

\subsection{Type of occupation and dance}

The survey provides two different approaches of measuring the level of interest people have in dance and the performing arts. First, it provides information regarding expenditure on performing arts tickets. This category does not only cover dance performances but other performing arts, however in data terms it is the closest available. All of the respondents declared to have incurred some form of expenditure in relation to performing arts attendance. However, the majority (77\%), declared to have spent less than $\mathrm{Kr} .500$ (less than approximately $€ 70$ ), which is the lowest positive category. $13 \%$ of the respondents spent between Kr.500-999, 7\% spent Kr.1000-1999, whilst the remaining 3\% spent more than Kr.2000. on performing arts tickets. Second, the survey measures the attendance rate at ballet and dance performances. The attendance rate is measured by means of a discrete ordinal variable which comes on a four point scale (not at all, 1-2 times, 2-5 times and 6 or more times during the previous 12 months).

Table 1 summarizes the variables introduced for dancers and non-dancers. Not surprisingly, people who dance, exhibit around twice as high a frequency for attendance at ballet and dance performances, and this difference is statistically significant (p-value < 0.01). The difference between dancers and non-dancers is much less striking when it comes to expenditure for performing arts. In fact, people who dance spent somewhat less on theatrical performances than those who do not dance, with the difference being just on the border of the $90 \%$ confidence interval. As we shall see later, dancers earn typically less than non-dancers, which could possibly explain this difference.

\section{[Table 1 here]}

We look next at disaggregated employment categories and we present in Figure 2 the available information for expenditure on performing arts tickets and attendance rates at ballet and dance performances, in relation to the type of occupation of the respondents. Borgonovi (2012) finds that art education is highly correlated with art participation but not with attendance. In this survey's results, dancers are the most engaged dance audience and they are commonly skilled workers or students, and are in fact not necessarily individuals 
with dance education. In fact, the correlation between dance training and attendance is $13 \%$ whereas the correlation between dance training and dance participation is $69 \%$, which is in line with Borgonovi's result.

Among those who do not dance, the retired or self-employed are those who attend more dance performances. It is interesting that dancers in these two categories also report a lower attendance. Overall, retired individuals and students attend more dance performances, perhaps due to having more free time and discounts in the price of individual or season tickets.

Expenditure on performing arts is in general highest for civil servants and students and lowest for unemployed and unskilled individuals. In the sub-sample of dancers, skilled workers, followed by civil servants, are those who present the highest expenditure level, whereas the lowest is for the categories of self-employed and unskilled workers.

Cheng and Wen (2011) show that theatre audiences are different from those of other performing arts, which may partly explain the difference between ballet and dance performance attendance and performing arts expenditure in general. The number of theatre plays may also help in explaining the results, but this data is unfortunately unavailable. Furthermore, little is known regarding seat purchases. It may be that civil servants attend less plays but purchase better seats in the theatre whereas it seems likely that students who pay at discounted prices, attend more plays but at a lesser cost.

\section{[Figure 2 here]}

\subsection{Dance types, expenditure and income}

The most popular dance type reported is sport-related dance (43 respondents), followed by folk (33), modern dance (18), hip-hop (8) and ballet (4). In the male category, the most reported dance types are sport and other types of dance, whereas the least reported are modern dance and salsa.

Figure 3 presents dance types in terms of average income, mean theatre expenses and mean attendance at dance performances. ${ }^{4}$ Individuals with a higher average income were more frequent dancers of salsa, ballet and hip-hop, while those with the lowest average income practice modern and sport-related dance.

Ballet dancers are those who attend more dance performances and have higher theatre expenditure, followed by salsa dancers. These results are likely to be correlated with the level of income. Individuals who dance folk and modern dance attend less dance performances and exhibit the lowest mean theatre expenditure.

Error! Reference source not found.depicts box plots of income across gender for dancers and non-dancers. Individuals who dance have statistically significant lower income. Montgomery and Robinson (2003) and Tobias (2004) avail of survey data for the USA and Germany, respectively, to show that there are very low returns to dance, low employment perspectives and a high dependence on economic variables (number of artists per dance group, mean fee and expenses of the group, other artistic staff and other expenses in technical staff and stage equipment). Our study bears some similitude in that the set of

\footnotetext{
${ }^{4}$ Income is measured with a discrete ordinal variable which comes on an eight point scale (beginning with "below Kr.300.000." and then increasing for each interval by Kr.100.000 up to the category of "over Kr.900.000.”). The mean income category is equal to 2.43 and is based on 1505 observations.
} 
dancers we observed may belong in part to a lower income group of professional or semiprofessional dancers.

\section{[Figures 3 and 4 here]}

\subsection{The age effect}

Error! Reference source not found.5 shows box plots for age across gender for dancers and non-dancers. It is observed that half of the population of dancers is above 40 years of age. It is further interesting to observe that both genders, but particularly older males dance relatively more. The mean age difference between dancers and non-dancers is 4.9 years and is statistically significant. This insight may perhaps help to explain the previously observed patterns of lower incomes for dancers. Since a high proportion of dancers are people at retirement age, these may receive lower incomes in general than those in employment.

To further investigate the effect of age on dance activities, Error! Reference source not found. shows the mean of respondents' age per dance style. It is perhaps not surprising that the majority of the older age groups dance folk. Danish folklore is embedded in the country's culture and folk dancing, dating back to the early $20^{\text {th }}$ century, is part of the national heritage. According to The National Association of Danish Folk Dancers (2014), in 2011, there were 12,000 active folk dancers affiliated to 219 clubs in Denmark. ${ }^{5}$ The second highest mean age is sport-related dance, which includes activities such as aerobics and Zumba, which are growing in popularity. As one might expect, the most common dance types amongst the younger generation are ballet and hip-hop. This could be a result of a higher demand for a degree of fitness, as well as, in the case of hip-hop, be a reflection of music tastes. The participation of the young in ballet has to be interpreted with caution, as the average age is based only on a small number of observations.

Figure 7 exhibits the relationship between attendance at ballet performances or expenditure on the performing arts and age. Correlations between either pairs of variables are positive and statistically significant, implying that ballet attendance increases with age ( $\mathrm{p}$-value $\approx 0.05)$, as well as the overall expenditure for the performing arts ( $\mathrm{p}$-value $<0.01)$.

\section{[Figures 5-7 here]}

\subsection{Dancing and other cultural consumptions}

One interesting question deals with the consumption patterns of other cultural attractions. Figure 8 shows some stylized differences between those who dance and those who do not with respect to the consumption of other cultural goods. Dancers clearly read more books, especially during the weekend, revealing a highly significant difference ( $\mathrm{p}$ value < 0.01). Those who dance also play more video games and the difference is again statistically significant ( $p$-value $<0.01$ ). This is also consistent with the insights of Borowiecki and Prieto-Rodriguez (2015a, 2015b) on the complementarity between video games playing and various cultural engagements. Finally, dancers are more frequent

\footnotetext{
${ }^{5}$ See Bochenek (2013) for a broader analysis of folk dancers, involving 259 individuals in 12 countries across the world.
} 
visitors to both art galleries and art exhibitions, although these differences are marginally outside the usual confidence intervals ( $\mathrm{p}$-value $<0.14$ ). In contrast, individuals who dance use internet significantly less ( $\mathrm{p}$-value $<0.01$ ), which could be associated with the typically higher age of dancers. Those who dance tend to dedicate less time to listening to music and visiting museums, albeit those differences are not statistically significant.

\section{Conclusions}

The labour markets related to dance consist of dancers, teachers, choreographers, technicians and managers. Nevertheless, many other individuals choose to dance as a hobby or as a second job. TV shows such as Strictly come dancing and So you think you can dance have helped to dramatically rise dance audiences and dancing is becoming increasingly popular as a leisure time activity.

This study, by availing of an information database on cultural preferences and habits in Denmark for 2004, illustrates the profiles of dancers and dance audiences and so deepens the current knowledge on the functioning of the dance market.

The most popular types of dance are sport/ballroom and folk dance, while the least favourite are hip-hop and ballet, which are also performed by the younger generation. The older generation's preferred type of dance is folk, which appears to be very popular in Denmark. Those with the highest income are more likely to practice salsa, hip-hop and ballet, while the poorer mostly choose sport/ballroom and modern dance. It is also shown that older and poorer individuals dance considerably more. Interestingly, dancers read significantly more, as well as play more video games and are more frequent visitors to art galleries and exhibitions, whereas non-dancers spend more time on the internet.

Individuals with dance training are further more likely to participate in dance classes, socials and/or performances but only $13 \%$ actually attend performances. Nonetheless, and perhaps not surprisingly, dancers (regardless of dance training) are the most assiduous dance audience. These audiences are typically skilled workers, students and civil servants. Regarding dance types, dancers who attend dance performances and plays tend to practice ballet, hip-hop and salsa whereas modern and folk dancers seem to avail themselves less of the performing arts.

The reasons which might explain the decision behind attending a dance performance or a theatre play are not explored in the survey, but may serve to justify some of the patterns discussed. While some individuals may be interested in intellectual or emotional stimulation, others may simply wish to use performing arts as a way to socialize. Overall, the disclosed results might reflect the fact that dance performances are particularly attractive to those who have more free time or to those who can purchase tickets at a reduced price. Since low attendance rates make it harder for dancers and dance companies to be sustainable in the long-run, it is of extreme importance to increase dance attendance. Some possible activities that may contribute to increasing or maintaining attendance rates are open rehearsals, heterogeneous pricing policies allowing for discounted ticket prices or special family or season packages. Furthermore, although dancers are typically interested in attendance at the performing arts, they usually have limited purchasing ability due to their low incomes and hence, the introduction of special deals for dance schools might constitute another supportive policy. Finally, as shown by Bakshi and Throsby (2014), the availability of digital technologies and providing access to dance performances via the internet or digital mediums might influence attendance rates positively and could even lead to 
increased physical attendance. Another way to stimulate dance audiences may be via fiscal discounts or subsidies (e.g. Borowiecki and Navarrete, 2015), particularly since dancing comes with a positive externality. 


\section{References}

Abdallah S., Michaelson J., Shah S., Stoll L., and Marks N. (2012). The Happy Planet Index: 2012 Report. A global index of sustainable well-being. London: New Economics Foundation.

Aoyam, Y. (2009). Artists, Tourists, and the State: Cultural Tourism and the Flamenco Industry in Andalusia, Spain. International Journal of Urban and Regional Research, 331, 80-104.

Ateca-Amestoy, V. (2008). Determining heterogeneous behavior for theatre attendance. Journal of Cultural Economics, 32(2), 127-151.

Bagashi, A. and Michapondwa, E. (2009). What actions could boost international tourism demand for Tanzania? University of Cape Town, Working Paper 152.

Bakshi, H. and Throsby, D. (2014). Digital complements or substitutes? A quasi-field experiment from the Royal National Theatre. Journal of Cultural Economics, 38(1), 1-8.

Bochenek, M. (2013). Festival Tourism of Folk Group Dancers from Selected Countries of the World. Polish Journal of Sport and Tourism, 20(2), 95-99.

Borgonovi, F. (2004). Performing arts attendance: an economic approach. Applied Economics, 36(17), 1871-1885.

Borowiecki, K.J. and Navarrete, T. (2015). Fiscal and Economic Aspects of Book Consumption in the European Union, ACEI Working Paper 02-2015.

Borowiecki, K.J. and Prieto-Rodriguez, J. (2015); Video Games Playing: A substitute for cultural consumptions? Journal of Cultural Economics, forthcoming. http://dx.doi.org/10.1007/s10824-014-9229-y

Borowiecki, K.J. and Prieto-Rodriguez, J. (2016). The Cultural Value and Variety of Video Games Playing. In J. Prieto-Rodriguez, V.M. Ateca-Amestoy, V. Ginsburgh, I. Mazza and J. O'Hagan (Eds.), Enhancing Cultural Participation in the EU. Challenges and Methods. Heidelberg: Springer, forthcoming 2016.

Cheng, T. and Wen, W. (2011). Determinants of performing arts attendance in Taiwan: a multivariate probit analysis. Applied Economics Letters, 18(15), 1437-1442.

Cheng, T. and Wen, W. (2013). Performing arts attendance in Taiwan: who and how often? Journal of Cultural Economics, 2013, 37(2), 309-325.

Colome, D. (2005). East Dance - West dance. Asia Europe Journal, 3, 247-257.

Forbes (2013). The Legatum Prosperity Index. Legatum Institute.

Eurostat, 2011. Cultural Statistics, Population and social conditions pocketbooks. Luxembourg: Publications Office of the European Union.

Grisolia, J. and Willis, K. (2012). A latent class model of theatre demand. Journal of Cultural Economics, 36(2), 113-139.

Hagoort, G. (2003). Pioneering Minds Worldwide: On the Entrepreneurial Principles of the Cultural and Creative Industries. The University of Chicago Press Books (Eburon Publishers, Delft)

Janaki, S. (2012); Socio-Economic Issues of Dancers: Now. Paper presented at the seminar on "Socio-economic issues of Dancers: Then and Now" organized by the Association of Bharatanatyam Artistes of India (ABHAI) on 28 April at the mini hall of the NaradaGana Sabha in Chennai.

Montgomery, S. and Robinson, M. (2003). What becomes of undergraduate dance majors? Journal of Cultural Economics, 27(1), 57-71. 
Nicolau, J. (2010). Culture-sensitive tourists are more price insensitive. Journal of Cultural Economics, 34(3), 181-195.

Palma, M., Luis, P. and Aguado, L. (2013). Determinants of cultural and popular celebration attendance: the case study of Seville Spring Fiestas. Journal of Cultural Economics, 37(1), 87-107.

Pilcher, K. (2012). Performing in a Night-Time Leisure Venue: a Visual Analysis of Erotic Dance. Sociological Research Online, 17(2), 19.

Răvar, A. and Mahika, C. (2013). What motivates cultural tourists? An analysis of Bucharest inhabitants' motivation to visit the centre region. Annals of Faculty of Economics, 1(1), 825-834.

Ross, A. and Butterfield, S. (1989). The Effects of a Dance Movement Education on Selected Psychomotor Skills of Children in Grades K-8. Research in Rural Education, 6(1), 51-56.

Schimmelpfennig, J. (1997). Demand for Ballet: A Non-Parametric Analysis of the 1995 Royal Ballet Summer Season. Journal of Cultural Economics, 21(2), 119-127.

Seaman, B. (2003). Cultural and Sport Economics: Conceptual Twins? Journal of Cultural Economics, 27(2), 81-126.

Skinner, J. (2013). Social Dance for Successful Aging: The Practice of Health, Happiness, and Social Inclusion Amongst Senior Citizens. Anthropology and Aging Quarterly, 34(1), 18-29

Swartz, T. (2007). Improved Draws for Highland Dance. Journal of Quantitative Analysis in Sports, 3(1), article 2.

The National Association of Danish Folk Dancers (LandsforeningenDanskeFolkedansere) (2014). http://www.folkedans.dk/ (accessed 20th April 2014).

Tobias, T. (2004). Quality in the Performing Arts: Aggregating and Rationalizing Expert Opinion. Journal of Cultural Economics, 28(2), 109-124.

Villella, E. (1994) Dance: from folk to classical. IDB Cultural Center, August 1994, Volume 7. 


\section{Tables and Figures}

\begin{tabular}{|c|c|c|c|c|c|c|}
\hline & \multicolumn{3}{|c|}{ Dance attendance $(0-3)$} & \multicolumn{3}{|c|}{ Performing arts expenditure (1-7) } \\
\hline & Obs. & Mean & Std. Err. & Obs. & Mean & Std. Err. \\
\hline Entire sample & 578 & 0.28 & $(0.02)$ & 1549 & 1.37 & $(0.02)$ \\
\hline Dancer & 40 & 0.48 & $(0.11)$ & 118 & 1.28 & $(0.06)$ \\
\hline Non-dancer & 538 & 0.27 & $(0.02)$ & 1431 & 1.38 & $(0.02)$ \\
\hline Difference & & $0.21 * * *$ & $(0.09)$ & & $-0.10 *$ & $(0.07)$ \\
\hline
\end{tabular}

Note: $* * *$ and $*$ indicate estimates that are significantly different from zero at,99 and 90 percent confidence intervals, respectively.

Table 1- Dance attendance and performing arts expenditure for dancers and non-dancers.

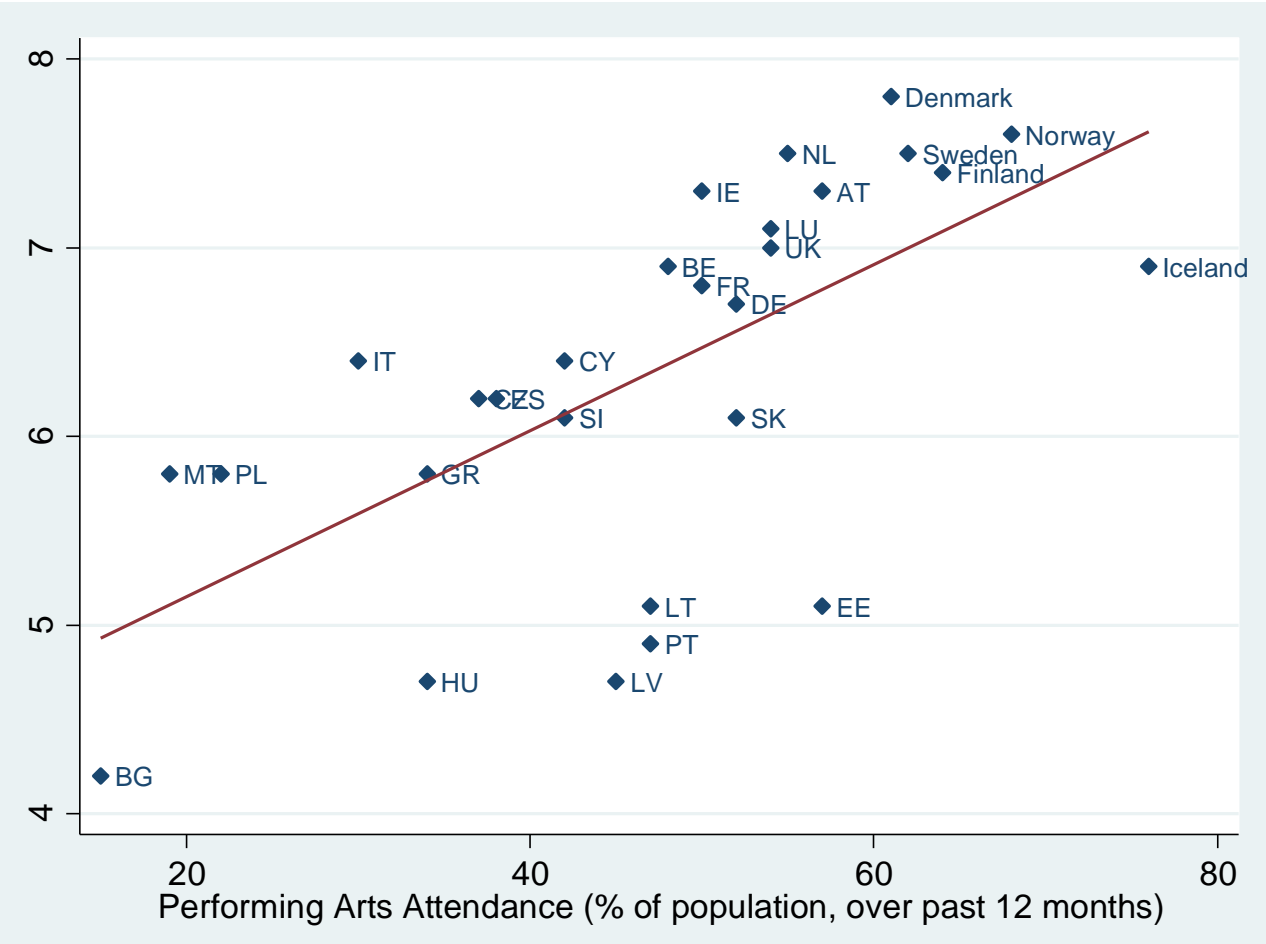

Figure 1-Well-being and attendance at performing arts in Europe. 


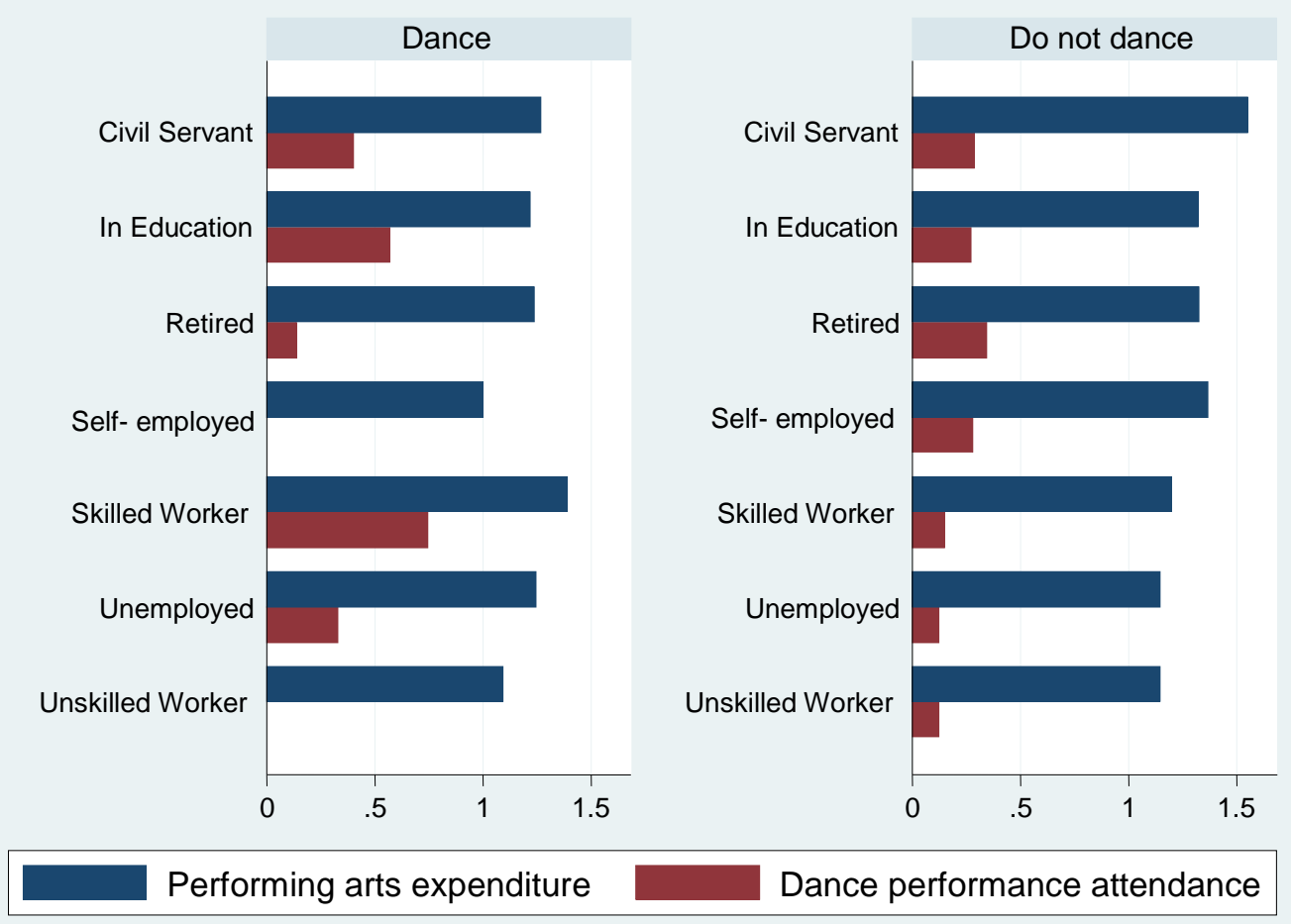

Error!

\section{Reference source not found.}

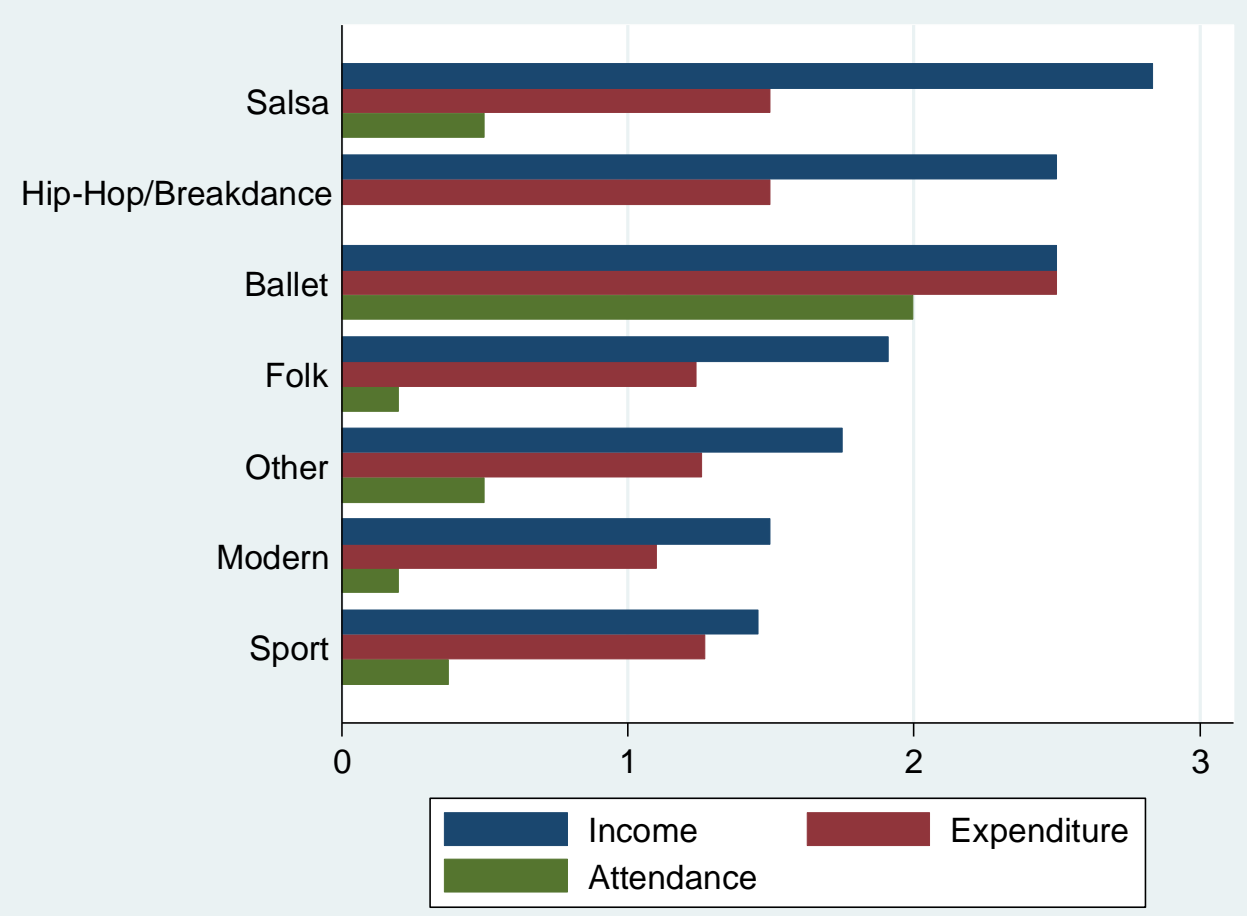

Figure 3 - Income, dance attendance and performing arts expenditure by types of dances. 


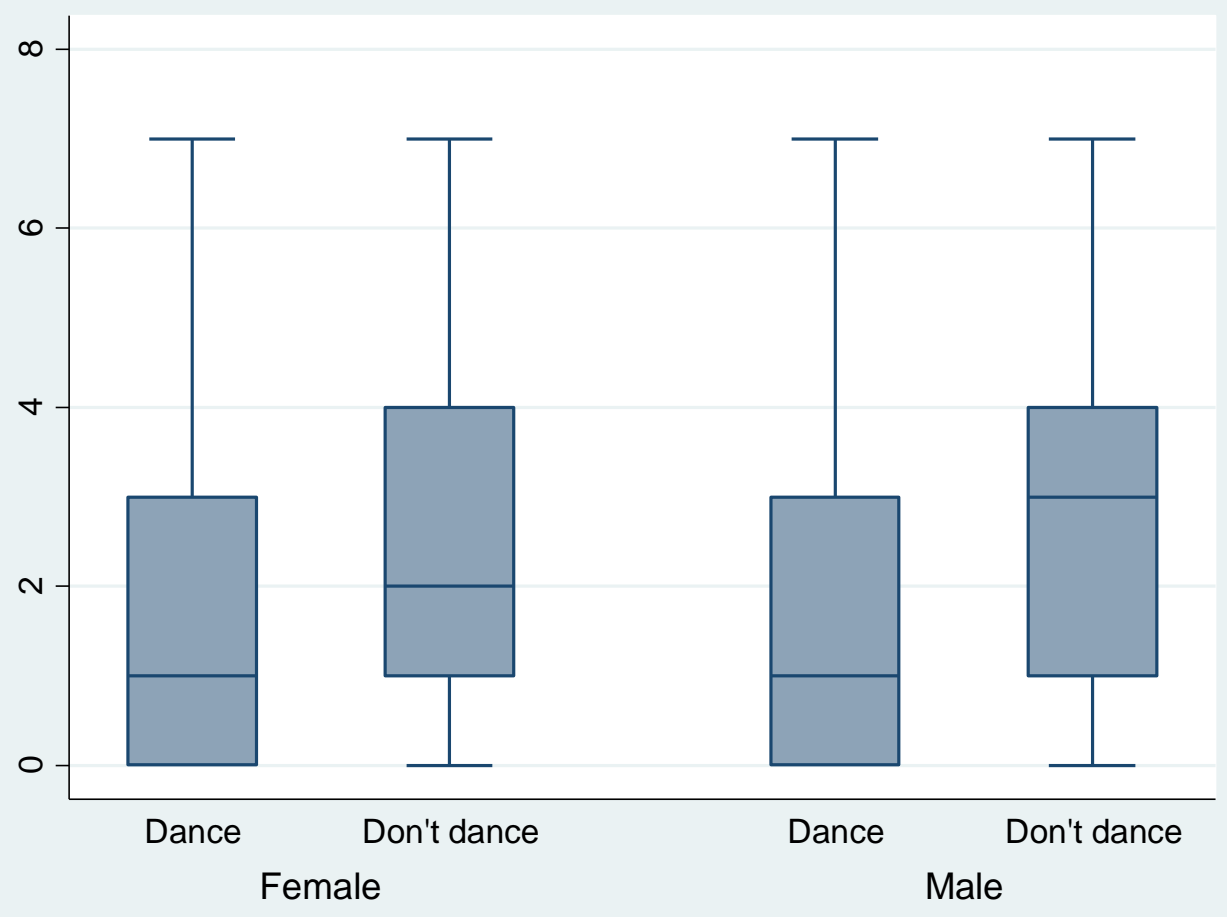

Figure 4- Income distribution by gender, for dancers and non-dancers.

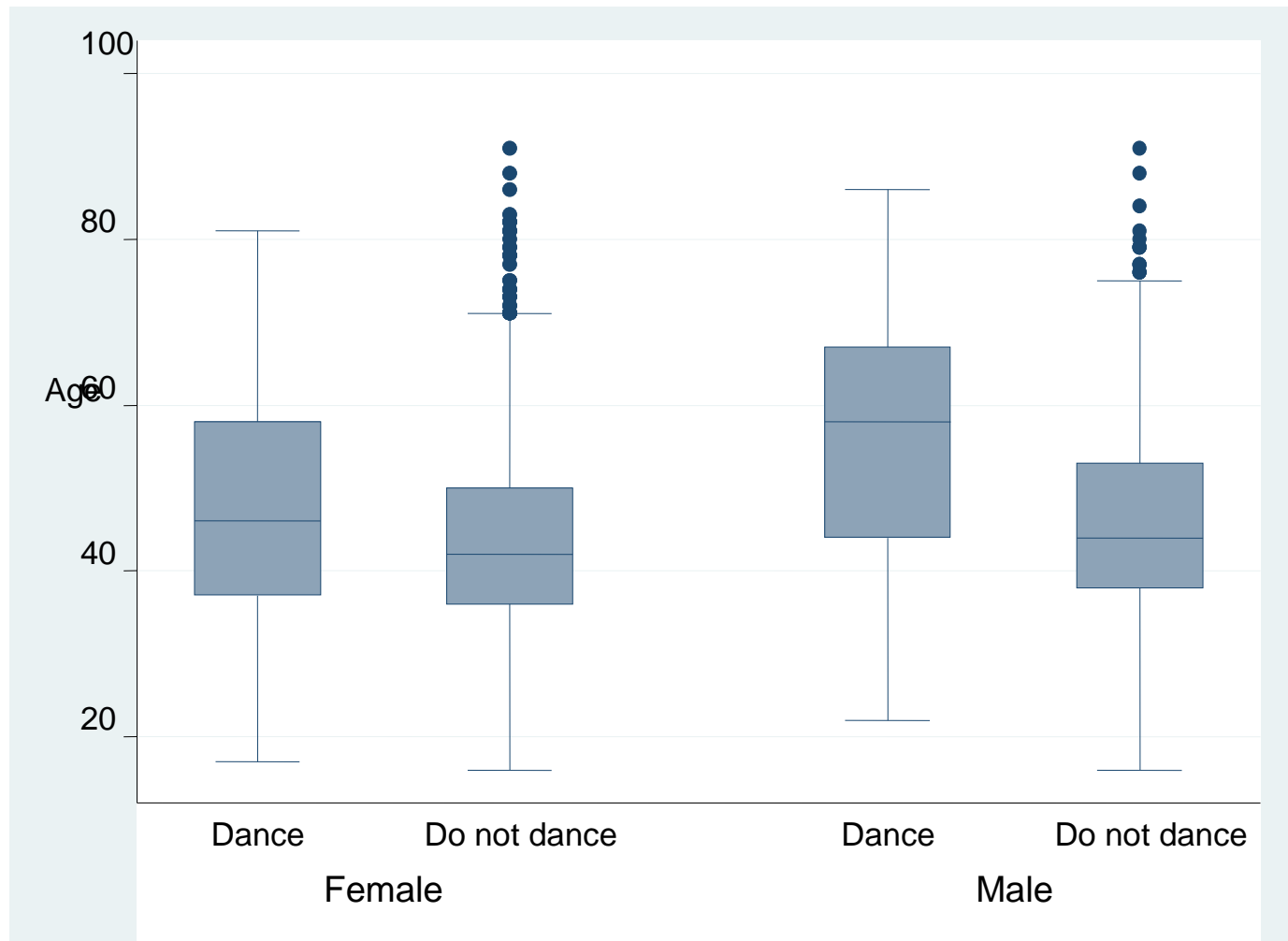

Figure 5 - Age distribution by gender, for dancers and non-dancers. 


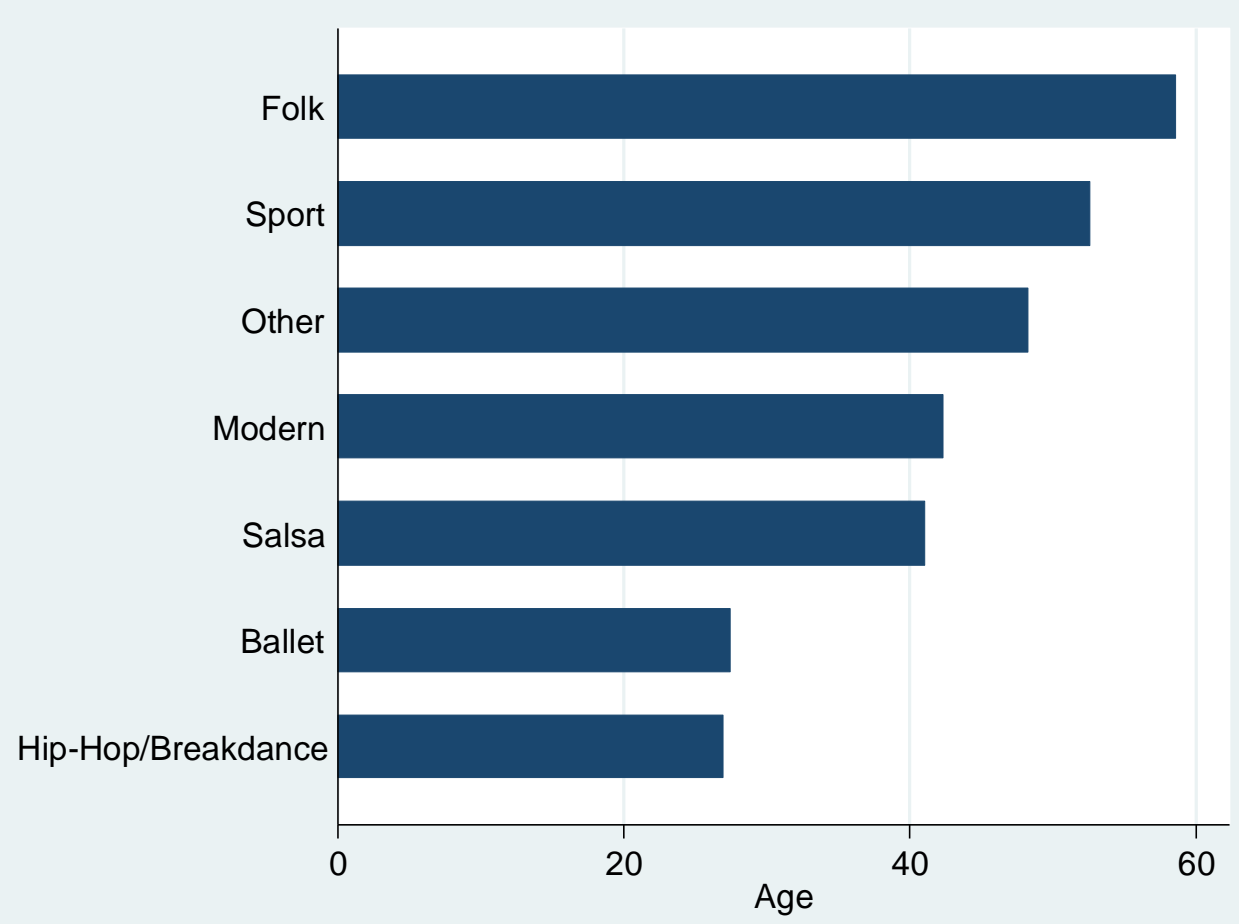

Figure 6 - Mean age by dance type.

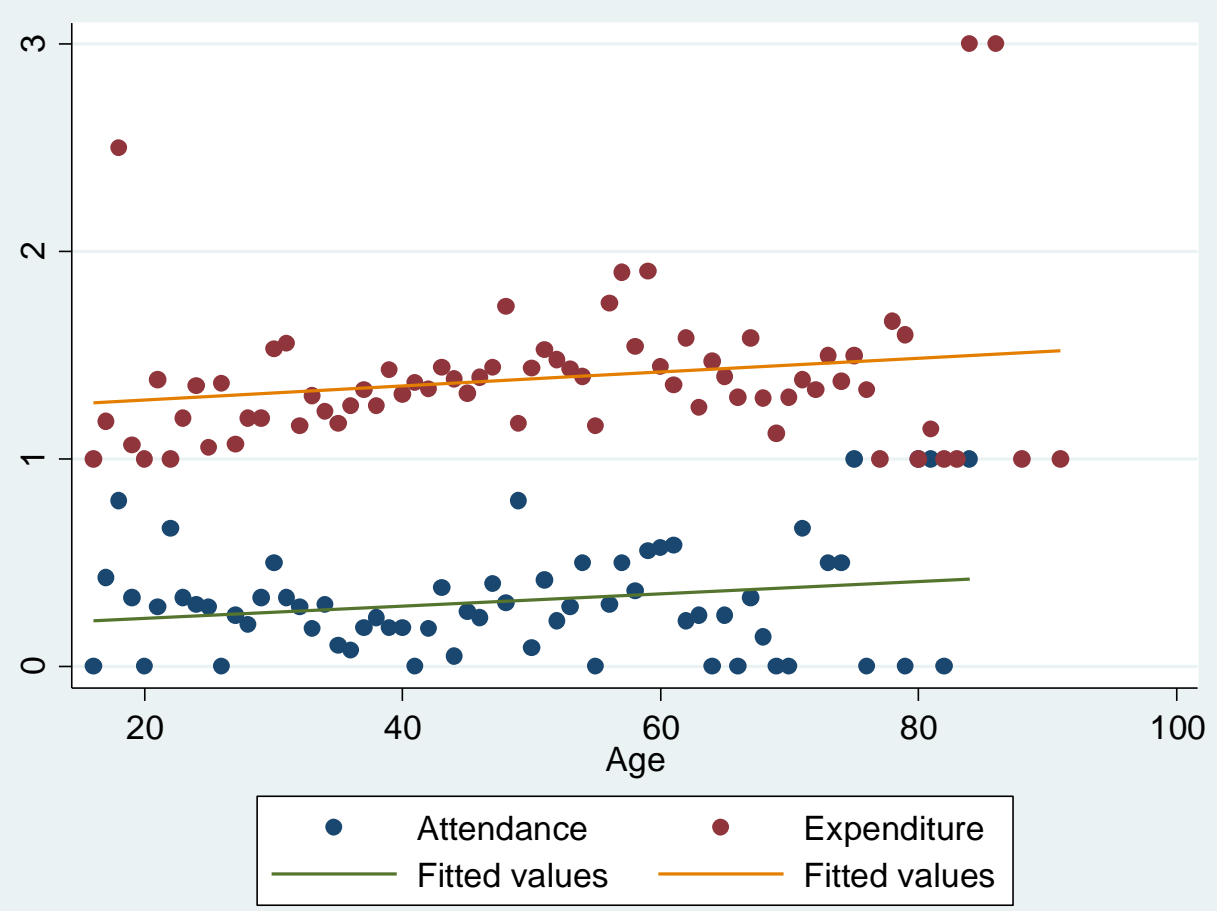

Figure 7-Dance attendance and performing arts expenditure by age. 


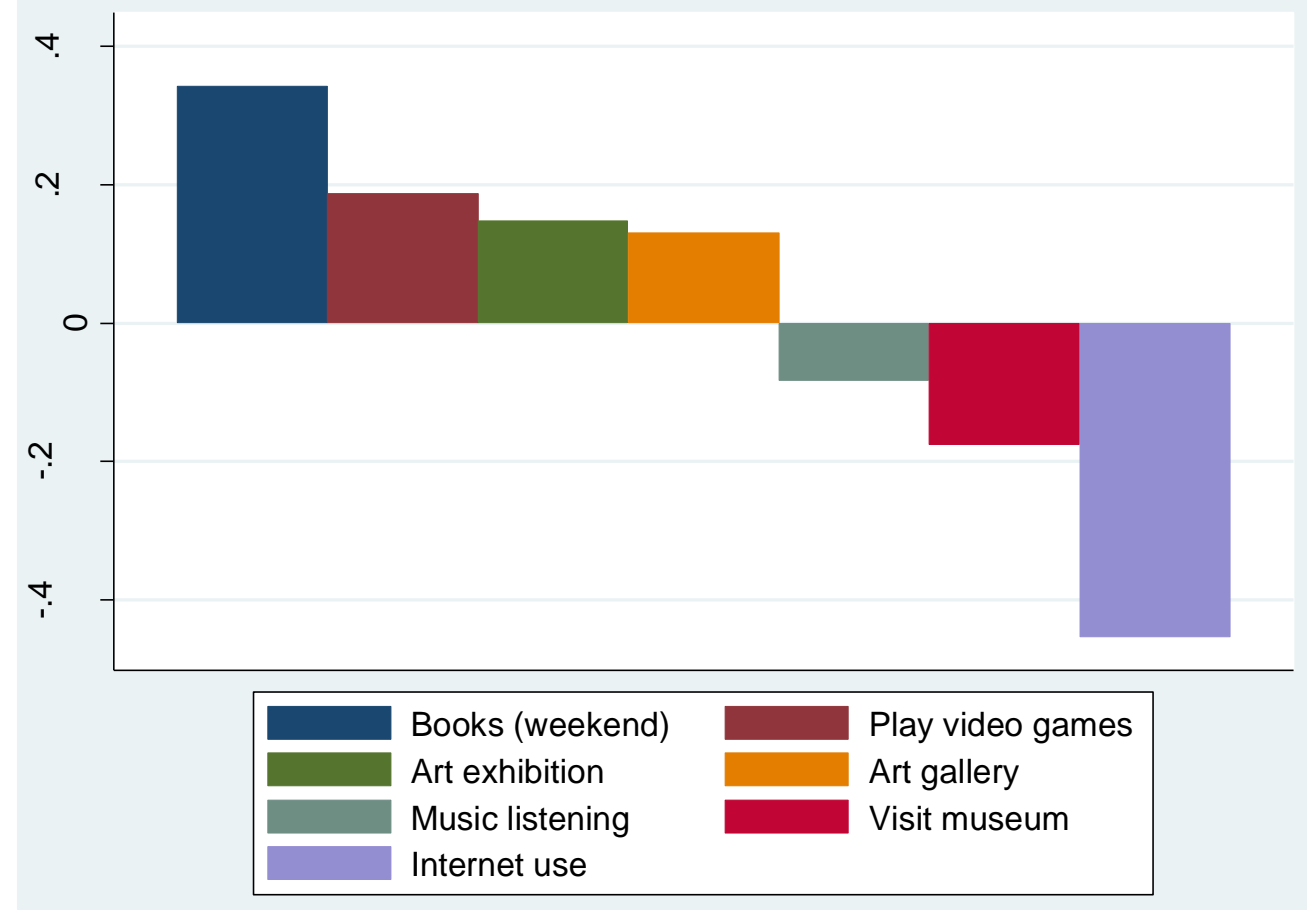

Figure 8 - Cultural consumptions, for dancers and non-dancers. 